\title{
Computational Studies for Inhibitory Action of 2-Mercapto-1-Methylimidazole Tautomers on Steel Using of Density Functional Theory Method (DFT)
}

\author{
Tappa Vinod Kumar ${ }^{1}$, John Makangara ${ }^{1}$, C. Laxmikanth ${ }^{2}$, Numbury Surendra Babu ${ }^{1}$ \\ ${ }^{1}$ Department of Chemistry, College of Natural and Mathematical Sciences, the University of Dodom, Dodoma, Tanzania \\ ${ }^{2}$ Department of Physics, College of Natural and Mathematical Sciences, the University of Dodoma, Dodoma, Tanzania
}

\section{Email address:}

nsbabusk@gmail.com (N. S. Babu), surendrababu.numbury@ac.tz (N. S. Babu)

\section{To cite this article:}

Tappa Vinod Kumar, John Makangara, C. Laxmikanth, Numbury Surendra Babu. Computational Studies for Inhibitory Action of 2Mercapto-1-Methylimidazole Tautomers on Steel Using of Density Functional Theory Method (DFT). International Journal of Computational and Theoretical Chemistry. Vol. 4, No. 1, 2016, pp. 1-6. doi: 10.11648/j.ijctc.20160401.11

Received: June 2, 2016; Accepted: June 16, 2016; Published: July 15, 2016

\begin{abstract}
The inhibition activity of thione-thiol tautomers of 2-mercapto-1-methylimidazole (MMI), namely 1-methyl-1Himidazole-2 (3H)-thione (M1) and 1-methyl-1H-imidazole-2-thiol (M2) has been performed using density functional theory (DFT) B3LYP/6-311G (d, P) basis set level in order to elucidate the different inhibition efficiencies of these compounds as corrosion inhibitors. The calculated structural parameters correlated to the inhibition efficiency are the frontier molecular orbital energies $\mathrm{E}_{\text {номо }}$ (Highest occupied molecular orbital energy), $\mathrm{E}_{\mathrm{LUMO}}$ (Lowest unoccupied molecular orbital energy), energy gap $(\Delta \mathrm{E})$, dipole moment $(\mu)$, hardness $(\eta)$, softness $(S)$, the absolute electronegativity $(\chi)$, the electrophilicity index $(\omega)$ and the fractions of electrons transferred $(\Delta \mathrm{N})$ from thione-thiol tautomer molecules to iron. The highest value of $\mathrm{E}_{\text {номо }}$ is $5.30241(\mathrm{eV})$ of M1 indicates the better inhibition efficiency than the other inhibitor M2. In our study, the trend for the $\left(\Delta \mathrm{E}_{\mathrm{g}}\right.$ gap) values follows the order M1>M2, which suggests that inhibitor M1 has the highest reactivity in comparison to M2 and would therefore likely interact strongly with the metal surface. The parameters like hardness $(\eta)$, Softness (S), dipole moment $(\mu)$, electron affinity (EA) ionization potential (IE), electronegativity $(\chi)$ and the fraction of electron transferred $(\Delta \mathrm{N})$ confirms the inhibition efficiency in the order of M1>M2.
\end{abstract}

Keywords: 2-Mercapto-1-Methylimidazole, Thione-Thiol Tautomers, Molecular Descriptors, HOMO-LUMO Energies and Density Functional Theory Method

\section{Introduction}

Methimazole (MMI) (2-mercapto-1-methylimidazole) is known to have several chemotherapeutic applications, particularly in the treatment of thyroid disorders. The reactions and coordination ability of $\mathrm{S}$, N-containing heterocyclic ligands such as MMI have been of considerable interest both from the structural point of view and pharmacological importance [1]. It is also taken before thyroid surgery or radioactive iodine therapy. Grave's disease is the most common cause of hyperthyroidism. It is an autoimmune disease resulting from antibodies that attach to receptors on thyroid hormone producing cells in the thyroid gland and trigger over production of thyroid hormone. An enzyme (peroxidase) produces thyroid hormones, i.e., thyroxine (T4) and triiodothyronine (T3), by combining iodine with a protein called thyroglobulin. MMI prevents iodine and peroxidase from their normal interactions with thyroglobulin to form $\mathrm{T} 4$ and $\mathrm{T} 3$. This action decreases thyroid hormone production. MMI also interferes with the conversion of T4 to T3. Since T3 is more potent than T4, this also reduces the activity of thyroid hormones $(2,3)$. But MMI may cause side effects such as nephritis, liver cirosis, skin irritation, allergies and pharyng with fever. Thus, accurate determination of the drug by using simple and fast methods is a requirement in the fields of pharmaceuticals, nutrition, as well as clinical chemistry. MMI exists in thiol and thione tautomeric forms (Figure 1) and consequently acts as ambidentate ligand. 


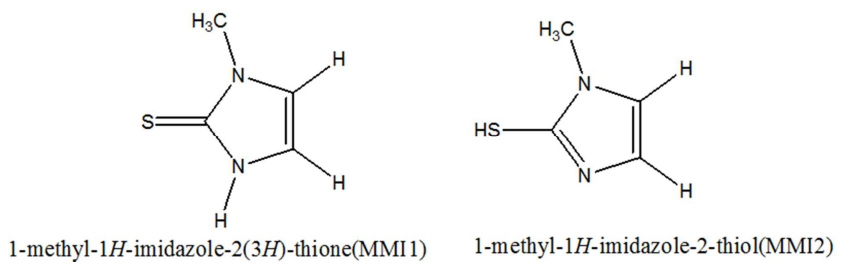

Fig. 1. The tautomeric forms of MMI.

Quantum chemical methods have already proven to be very useful in determining the molecular structure as well as elucidating the electronic structure and reactivity [4]. Thus, it has become a common practice to carry out quantum chemical calculations in corrosion inhibition studies. The concept of assessing the efficiency of a corrosion inhibitor with the help of computational chemistry is to search for compounds with desired properties using chemical intuition and experience into a mathematically quantified and computerized form. Once a correlation between the structure and activity or property is found, any number of compounds, including those not yet synthesized, can be readily screened employing computational methodology [5] and a set of mathematical equations which are capable of representing accurately the chemical phenomenon under study $[6,7]$.

The study of corrosion processes and their inhibition by organic inhibitors is a very active field of research [8]. Many researchers report that the inhibition effect mainly depends on some physicochemical and electronic properties of the organic inhibitor which relate to its functional groups, steric effects, electronic density of donor atoms, and orbital character of donating electrons, and so on [9, 10]. The inhibiting mechanism is generally explained by the formation of a physically and/or chemically adsorbed film on the metal surface $[11,12]$. It is well known that organic compounds which act as inhibitors are rich in hetero atoms, such as sulfur, nitrogen, and oxygen $[13,14]$. These compounds and their derivatives are excellent corrosion inhibitors in a wide range of media and are selected essentially from empirical knowledge based on their macroscopic physico-chemical properties. Recently, theoretical prediction of the efficiency of corrosion inhibitors has become very popular in parallel with the progress in computational hardware and the development of efficient algorithms which assisted the routine development of molecular quantum mechanical calculations [15]. Due to the enormous complexity of this type of studies which need to consider the metallic surface, inhibitor and solvent molecules, theoretical calculations of the corrosion inhibition processes cannot be achieved in a rigorous way from the viewpoint of quantum chemistry.

\section{Computational Details}

All the geometries of the tautomers have been fully optimized using the B3LYP method within the framework of density functional theory (DFT) in conjunction with the 6$311 \mathrm{G}(\mathrm{d}, \mathrm{p})$ basis set, i.e., Becke's three parameter non-local hybrid exchange potential with the non-local correlation functional of Lee, Yang, and Parr [16, 17]. Following the geometry optimizations, analytical frequency calculations were proceeded at the DFT/6-311G (d, p) level, using following standard procedures, to obtain the thermochemical properties. All these calculations were carried out on a Pentium V personal computer by means of GAUSSIAN 09 program package [18]. These calculations have been widely used to study reaction mechanisms [19]. They have also been proved to be a very powerful tool for studying inhibition of the corrosion of metals [20, 21]. Recently, density functional theory (DFT) has been used to analyze the characteristics of the inhibitor/surface mechanism and to describe the structural nature of the inhibitor in the corrosion process [22].

\section{Global and local reactivity descriptors}

The basic relationship of the density functional theory of chemical reactivity is precisely, the one established by Parr, Donnelly, Levy and Palke [23], that links the chemical potential of DFT with the first derivative of the energy with respect to the number of electrons, and therefore with the negative of the electronegativity $(\chi)$.

$$
\chi=-\mu=\left(\frac{\partial E}{\partial N}\right)_{V(\vec{r})}
$$

Where $\mu$ is the chemical potential, $\mathrm{E}$ is the total energy, $\mathrm{N}$ is the number of electrons, and $v(r)$ is the external potential of the system. Hardness $(\eta)$ has been defined within the DFT as the second derivative of the $\mathrm{E}$ with respect to $\mathrm{N}$ as $\left(\mathrm{v}_{\mathrm{r}}\right)$ property which measures both the stability and reactivity of the molecule [24].

$$
\eta=\frac{1}{2}\left(\frac{\partial^{2} E}{\partial N^{2}}\right)_{V(\vec{r})}
$$

Where, $\mathrm{v}(\mathrm{r})$ and $\mu$ are the external and electronic chemical potentials respectively.

According to, the Koopmans' theorem [25] for closed-shell molecules, ionization potential (IP) and electron affinity (EA) can be expressed as follows in terms of $\mathrm{E}_{\mathrm{HOMO}}$ and $\mathrm{E}_{\mathrm{LUMO}}$, the highest occupied molecular orbital energy, and the lowest unoccupied molecular orbital energy, respectively:

$$
I P=-E_{\text {НОмО }} \text { and } E A=-E_{L U M O}
$$

When the values of IP and EA are known, one can determine through the following expressions [26] the values of the absolute electronegativity $\chi$, the absolute hardness $(\eta)$ and the softness $(\mathrm{S})$ :

$$
\chi=\frac{I+A}{2} \text { and } \eta=\frac{I-A}{2}
$$

The global softness (s) is the inverse of the global hardness [27].

$$
S=\frac{1}{\eta}
$$

The electrophilicity is a descriptor of reactivity that allows 
a quantitative classification of the global electrophilic nature of a molecule within a relative scale. Parr have proposed electrophilicity index as a measure of energy lowering due to maximal electron flow between donor and acceptor and defined electrophilicity index $(\omega)$ as follows [28].

$$
\omega=\frac{\mu^{2}}{2 \eta}
$$

Moreover, for a reaction of two systems with different electronegativities, the electronic flow will occur from the molecule with the lower electronegativity (the organic inhibitor) towards that of higher value (metallic surface), till the chemical potentials are equal [29]. Therefore the fraction of electrons transferred $(\Delta \mathrm{N})$ from the inhibitor molecule to the metallic atom was calculated according to Pearson electronegativity scale [29]:

$$
\Delta N=\frac{\chi_{F e}-\chi_{i n h}}{2\left(\eta_{F e}+\eta_{i n h}\right)}
$$

Where $\chi_{\mathrm{Fe}}$ and $\chi_{\mathrm{inh}}$ denote the absolute electronegativity of $\mathrm{Fe}$ and the inhibitor molecule, respectively; $\eta_{\mathrm{Fe}}$ and $\eta_{\text {jnh }}$ denote the absolute hardness of $\mathrm{Fe}$ and the inhibitor molecule, respectively. A theoretical value for the electronegativity of bulk iron was used $\chi_{\mathrm{Fe}}=7 \mathrm{eV}$ and a global hardness of $\eta_{\mathrm{Fe}}=0$, by assuming that for a metallic bulk $\mathrm{IP}=\mathrm{EA}$ because they are softer than the neutral metallic atoms [30].

According to the simple charge transfer model for donation and back-donation of charges proposed recently by Gomez et al., [31] an electronic back-donation process might be occurring governing the interaction between the inhibitor molecule and the metal surface. The concept establishes that if both processes occur, namely charge transfer to the molecule and backdonation from the molecule, the energy change is directly related to the hardness of the molecule, as indicated in the following expression.

$$
\Delta E_{\text {Back-donation }}=-\frac{\eta}{4}
$$

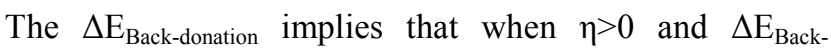
donation $<0$ the charge transfer to a molecule, followed by a back-donation from the molecule, is energetically favored. In this context, hence, it is possible to compare the stabilization among inhibiting molecules, since there will be an interaction with the same metal, then, it is expected that it will decrease as the hardness increases.

\section{Results and Discussion}

\subsection{Molecular Geometry}

The geometries for thione and thiol forms of MMI molecule were fully optimized at DFT level of theory using a B3LYP functional together with 6-311G $(\mathrm{d}, \mathrm{p})$ basis set in gaseous phase and the absence of imaginary frequencies in the vibrational spectrum proves that the equilibrium structures correspond to the minima energy for each tautomer. The final optimized geometries are given in Figure 2 and Table 1 represents the bond lengths and their angle measurement.

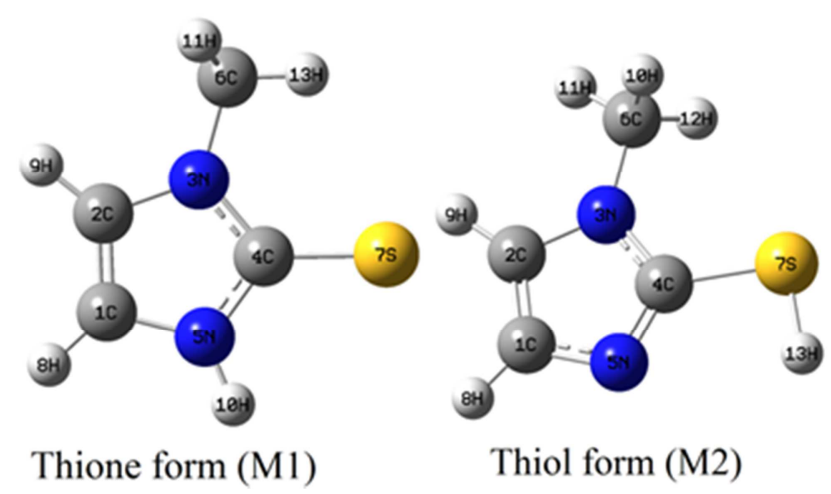

Fig. 2. The optimized geometries for thione (M1) and thiol (M2) form of MMI molecule at B3LYP/6-311G $(d, p)$ level.

\begin{tabular}{|c|c|c|c|}
\hline Thione (M1) & & Thiol (M2) & \\
\hline Bond angle & $\mathbf{A}^{0}$ & Bond angle & $\mathbf{A}^{0}$ \\
\hline $\mathrm{C} 2, \mathrm{C} 1, \mathrm{~N} 5$ & 106.4253 & $\mathrm{C} 2, \mathrm{C} 1, \mathrm{~N} 5$ & 110.6663 \\
\hline $\mathrm{C} 2, \mathrm{C} 1, \mathrm{H} 8$ & 130.8413 & $\mathrm{C} 2, \mathrm{C} 1, \mathrm{H} 8$ & 128.198 \\
\hline N5, C1, H8 & 122.7334 & N5, C1, H8 & 121.1352 \\
\hline $\mathrm{C} 1, \mathrm{C} 2, \mathrm{~N} 3$ & 107.6199 & $\mathrm{C} 1, \mathrm{C} 2, \mathrm{~N} 3$ & 105.7762 \\
\hline $\mathrm{C} 1, \mathrm{C} 2, \mathrm{H} 9$ & 130.4779 & $\mathrm{C} 1, \mathrm{C} 2, \mathrm{H} 9$ & 132.7166 \\
\hline $\mathrm{N} 3, \mathrm{C} 2, \mathrm{H} 9$ & 121.9022 & $\mathrm{~N} 3, \mathrm{C} 2, \mathrm{H} 9$ & 121.5068 \\
\hline $\mathrm{C} 2, \mathrm{~N} 3, \mathrm{C} 4$ & 110.3584 & $\mathrm{C} 2, \mathrm{~N} 3, \mathrm{C} 4$ & 105.9061 \\
\hline $\mathrm{C} 2, \mathrm{~N} 3, \mathrm{C} 6$ & 125.1623 & $\mathrm{C} 2, \mathrm{~N} 3, \mathrm{C} 6$ & 126.782 \\
\hline $\mathrm{C} 4, \mathrm{~N} 3, \mathrm{C} 6$ & 124.4792 & $\mathrm{C} 4, \mathrm{~N} 3, \mathrm{C} 6$ & 127.2723 \\
\hline $\mathrm{N} 3, \mathrm{C} 4, \mathrm{C} 5$ & 103.9812 & $\mathrm{~N} 3, \mathrm{C} 4, \mathrm{C} 5$ & 112.7043 \\
\hline $\mathrm{N} 3, \mathrm{C} 4, \mathrm{~S} 7$ & 129.191 & $\mathrm{~N} 3, \mathrm{C} 4, \mathrm{~S} 7$ & 121.5046 \\
\hline $\mathrm{N} 5, \mathrm{C} 4, \mathrm{~S} 7$ & 126.8279 & N5, C4, S7 & 125.791 \\
\hline $\mathrm{C} 1, \mathrm{~N} 5, \mathrm{C} 4$ & 111.6152 & $\mathrm{C} 1, \mathrm{~N} 5, \mathrm{C} 4$ & 104.9451 \\
\hline C1, N5, H10 & 127.1272 & N3, C6, H10 & 111.2832 \\
\hline $\mathrm{C} 4, \mathrm{~N} 5, \mathrm{H} 10$ & 121.2576 & N3, C6, H11 & 108.9344 \\
\hline N3, C6, H11 & 110.374 & N3, C6, H12 & 110.1391 \\
\hline N3, C6, H12 & 110.3401 & H10, C6, H11 & 108.9519 \\
\hline N3, C6, H13 & 107.5083 & H10, C6, H12 & 109.0422 \\
\hline H11, C6, H12 & 109.621 & H11, C6, H12 & 108.4346 \\
\hline H11, C6, H13 & 109.466 & C4, S7, H13 & 92.5963 \\
\hline H12, C6, H13 & 109.4974 & & \\
\hline Bond & $\mathbf{A}^{0}$ & Bond & $\mathbf{A}^{0}$ \\
\hline $\mathrm{C} 1-\mathrm{C} 2$ & 1.3514 & $\mathrm{C} 1-\mathrm{C} 2$ & 1.3665 \\
\hline C1-N5 & 1.385 & $\mathrm{C} 1-\mathrm{N} 5$ & 1.3779 \\
\hline $\mathrm{C} 1-\mathrm{H} 8$ & 1.0756 & $\mathrm{C} 1-\mathrm{H} 8$ & 1.0787 \\
\hline $\mathrm{C} 2-\mathrm{N} 3$ & 1.3911 & $\mathrm{C} 2-\mathrm{N} 3$ & 1.3873 \\
\hline C2-H9 & 1.0761 & C2-H9 & 1.0771 \\
\hline N3-C4 & 1.3764 & $\mathrm{~N} 3-\mathrm{C} 4$ & 1.3672 \\
\hline N3-C6 & 1.4533 & N3-C6 & 1.454 \\
\hline C4-N5 & 1.3703 & C4-N5 & 1.3119 \\
\hline C4-S7 & 1.6811 & C4-S7 & 1.7758 \\
\hline N5-H10 & 1.0065 & C6-H10 & 1.0934 \\
\hline C6-H11 & 1.0924 & C6-H11 & 1.0892 \\
\hline C6-H12 & 1.0923 & C6-H12 & 1.0918 \\
\hline C6-H13 & 1.0887 & N7-H13 & 1.3461 \\
\hline
\end{tabular}

Table 1. Optimized geometric parameters of thione form (M1) and hiol form (M2) molecules. 


\subsection{Global Molecular Reactivity}

According to the frontier molecular orbital theory (FMO) of chemical reactivity, transition of electron is due to interaction between highest occupied molecular orbital (HOMO) and lowest unoccupied molecular orbital (LUMO) of reacting species [32]. Table 2 represents the quantum chemical parameters for the inhibitors M1and M2.

Table 2. Quantum chemical parameters for M1and M2 calculated using $B 3 L Y P / 6-311 G(d, p)$.

\begin{tabular}{lll}
\hline & Thione (M1) & Thiol (M2) \\
\hline HOMO (ev) & -5.30241 & -5.82052 \\
LUMO (ev) & 0.09143 & 0.06231 \\
$\mathrm{I}(\mathrm{ev})$ & 5.30241 & 5.82052 \\
$\mathrm{~A}(\mathrm{ev})$ & -0.09143 & -0.0623 \\
$\mathrm{X}(\mathrm{ev})$ & 2.60549 & 2.87910 \\
$\eta(\mathrm{ev})$ & 2.69692 & 2.94142 \\
$\mathrm{M}(\mathrm{ev})$ & -2.60549 & -2.87910 \\
$\mathrm{~S}(\mathrm{ev})$ & 0.37079 & 0.33997 \\
$\Omega(\mathrm{ev})$ & 1.25858 & 1.40905 \\
$\Delta \mathrm{N}(\mathrm{ev})$ & 0.81472 & 0.70049 \\
$\Delta \mathrm{en}(\mathrm{ev})$ & 1.35001 & 1.47137 \\
$\Delta \mathrm{ee}(\mathrm{ev})$ & 6.56099 & 7.22957 \\
$\Delta$ Eg gap (ev) & -5.39384 & -5.88283 \\
$\Delta \mathrm{EBack}-\mathrm{donation}$ & -0.67423 & -0.735355 \\
$\mu^{*}($ dipole moment, debye) & 5.6629 & 3.0906 \\
polarizability & 74.63467 & 70.32867 \\
Hyper polarizability & $3.0908 \mathrm{X} 10-31$ esu & $1.5854 \mathrm{X} 10-31 \mathrm{esu}$ \\
Thermodynamic properties & & \\
The energy of change $(\Delta \mathrm{E}) \mathrm{Kcal} / \mathrm{mole}$ & 12.81457983 \\
The enthalpy of change $(\Delta \mathrm{H}) \mathrm{K}$ cal/mole & 10.6281284 \\
The change of free energy $(\Delta \mathrm{G}) \mathrm{K}$ cal/mole & 9.93975048 \\
The change of entropy $(\Delta \mathrm{S}) \mathrm{Cal} / \mathrm{Mol}-\mathrm{Kelvin}$ & 2.309 \\
\hline
\end{tabular}

The energy of the highest occupied molecular orbital $\left(\mathrm{E}_{\mathrm{HOMO}}\right)$ measures the tendency towards the donation of electron by a molecule. Therefore, higher values of $\mathrm{E}_{\text {Номо }}$ indicate better tendency towards the donation of electron, enhancing the adsorption of the inhibitor on mild steel and therefore better inhibition efficiency. $\mathrm{E}_{\mathrm{LUMO}}$ indicates the ability of the molecule to accept electrons. The binding ability of the inhibitor to the metal surface increases with increasing of the HOMO and decreasing of the LUMO energy values. Frontier molecular orbital diagrams of M1 and M2 is represented in fig. 3 .

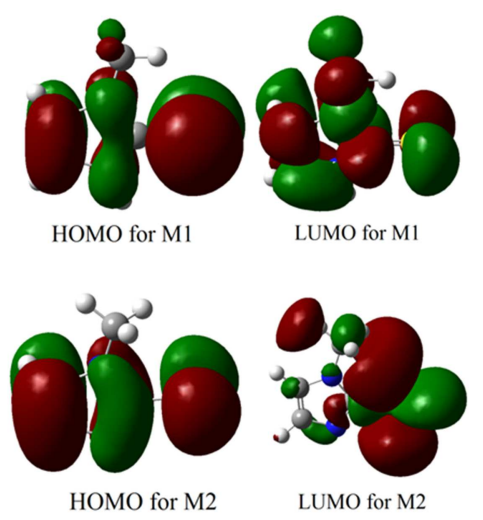

Fig. 3. Frontier molecular orbital diagrams of $P 1$ and $P 2$ by $B 3 L Y P / 6-311 G$ $(d, p)$.
The energy of the HOMO ( $\mathrm{E}_{\text {номо }}$ ) provides information about the electron donating ability of the molecule. The molecule with the highest $\mathrm{E}_{\text {Hомо value often has the highest }}$ tendency to donate electrons to appropriate acceptor molecule of low empty molecular orbital energy [33]. The inhibitor does not only donate electron to the unoccupied $d$ orbital of the metal ion but can also accept electron from the $\mathrm{d}$-orbital of the metal leading to the formation of a feedback bond. The highest value of $\mathrm{E}_{\text {Hомо }}$ is $-5.30241(\mathrm{eV})$ of M1, indicates the better inhibition efficiency than the other inhibitor M2.

The energy gap between the HOMO and the LUMO $(\Delta \mathrm{E})$ provides information about the overall reactivity of a molecule. As $\Delta \mathrm{E}$ decreases, the reactivity of the molecule increases leading to increase in the inhibition efficiency of the molecule [34]. Low values of the $\left(\Delta \mathrm{E}=\mathrm{E}_{\text {LUMO }}-\mathrm{E}_{\text {Hомо }}\right)$ gap will render good inhibition efficiencies since the energy to remove an electron from the last occupied orbital will be minimized [35]. A molecule with a low energy gap is more polarizable and is generally associated with the high chemical activity and low kinetic stability and is termed soft molecule [36]. In our study, the trend for the $\left(\Delta \mathrm{E}_{\mathrm{g}}\right.$ gap) values follows the order $\mathrm{M} 1>\mathrm{M} 2$, which suggests that inhibitor M1 has the highest reactivity in comparison to the other compound M2 and would therefore likely interact strongly with the metal surface.

Table 2 summarized the important global chemical parameters. Ionization energy is a fundamental descriptor of the chemical reactivity of atoms and molecules. High ionization energy indicates high stability and chemical inertness and small ionization energy indicates high reactivity of the atoms and molecules [37]. The low ionization energy $5.30241(\mathrm{eV})$ of M1 indicates the high inhibition efficiency.

Absolute hardness and softness are important properties to measure the molecular stability and reactivity. It is apparent that the chemical hardness fundamentally signifies the resistance towards the deformation or polarization of the electron cloud of the atoms, ions or molecules under small perturbation of chemical reaction. A hard molecule has a large energy gap and a soft molecule has a small energy gap [38]. In our present study M1 with low hardness value $2.69692(\mathrm{eV})$ compared with other compound have a low energy gap. Normally, the inhibitor with the least value of global hardness (hence the highest value of global softness) is expected to have the highest inhibition efficiency [39]. For the simplest transfer of electron, adsorption could occur at the part of the molecule where softness (S), which is a local property, has a highest value [40]. M1 with the softness value of 0.7079 has the highest inhibition efficiency.

Table 2 shows the order of electronegativity as M2 $>$ M1. Hence an increase in the difference of electronegativity between the metal and the inhibitor is observed in the order M1 $>$ M2. According to Sanderson's electronegativity equalization principle [41], M2 with a high electronegativity and low difference of electronegativity quickly reaches equalization and hence low reactivity is expected which in turn indicates low inhibition efficiency. 
The number of electrons transferred $(\Delta \mathrm{N})$ and backdonation $(\Delta \mathrm{E})$ was also calculated and tabulated in Table 2. Values of $\Delta \mathrm{N}$ show that the inhibition efficiency resulting from electron donation agrees with Lukovits's study [42]. If $\Delta \mathrm{N}<3.6$, the inhibition efficiency increases by increasing electron-donating ability of these inhibitors to donate electrons to the metal surface and it increases in the following order: M1 $>$ M2. Thus, the highest fraction of electrons transferred is associated with the best inhibitor (M1), while the least fraction is associated with the inhibitor that has the least inhibition efficiency (M2).

\section{Conclusion}

Quantum chemical calculations, using the Density Functional Theory method, have been performed on two pyrazole derivatives, namely 1-methyl-1H-imidazole-2 $(3 \mathrm{H})$ thione (MMI1) and 1-methyl-1H-imidazole-2-thiol (MMI2) to investigate their geometric and electronic properties in an attempt to elucidate the reactivity. The inhibition efficiency of $\mathrm{P} 1$ and $\mathrm{P} 2$ increases with the increase in EHOMO, and decreases in energy gap $(\Delta \mathrm{E})$. M1 has the highest inhibition efficiency because it had the highest HOMO energy and $\Delta \mathrm{N}$ values and it was most capable of offering electrons. The parameters like hardness $(\eta)$, Softness $(S)$, dipole moment $(\mu)$, electron affinity (EA) ionization potential (IE), electronegativity $(\chi)$ and the fraction of electron transferred $(\Delta \mathrm{N})$ confirms the inhibition efficiency in the order of M1>M2.

\section{References}

[1] Akrivos PD, Recent studies in the coordination chemistry of heterocyclicthiones and thionates. Coordination Chemistry Reviews. 213 (2001), 181-210.

[2] Marchant B, Lees JF and Alexander WD, Antithyroid drugs. Pharmacol. Ther. 3 (1978), 305-348.

[3] Nakamura H, Noh JY, Itoh K, Fukata S, Miyauchi A and Hamada N, Comparison of methimazole and propylthiouracil in patients with hyperthyroidism caused by graves' disease. J. Clin. Endocrinol. Metab. 92 (2007), 2157-2162.

[4] Kraka E and Cremer D, Computer design of anticancer drugs. J. Am. Chem. Soc. 122 (2000), 8245-8264.

[5] Karelson M and Lobanov V, Quantum chemical descriptors in QSAR/QSPR studies. Chem. Rev. 96 (1996), 1027-1043.

[6] Hinchliffe A, Modelling Molecular Structures, John Wiley \& Sons, New York, 1994.

[7] Hinchliffe A, Chemical Modelling From Atoms to Liquids, John Wiley \& Sons, New York, 1999.

[8] Bouayed M and Rabaa H Srhiri A, Saillard JY, and Ben Bachir A, Experimental and theoretical study of organic corrosion inhibitors on iron in acidic medium, Corros. Sci. 41 (1999), 501-517.

[9] Quraishi MA and Sardar R, Corrosion inhibition of mild steel in acid solutions by some aromatic oxadiazoles, Mater. Chem. Phys. 78 (2002), 425-431.
[10] Stupnišek-Lisac E, Podbršc `ek S and T. Soric 'T, Non-toxic organic zinc corrosion inhibitors in hydrochloric acid, J. Appl. Electrochem. 24 (1994), 779-784.

[11] Touhami F, Aouniti A, Abed Y, Hammouti B, Kertit S, Ramdani A and Elkacemi K, Corrosion inhibition of armco iron in $1 \mathrm{M} \mathrm{HCl}$ media by new bipyrazolic derivatives, Corros. Sci. 42 (2000), 929-940.

[12] Tang L, Li X, Li L, Mu G and Liu G, Interfacial behavior of 4-(2-pyridylazo) resorcin between steel and hydrochloric acid, Surf. Coat. Technol. 201 (2006), 384-388.

[13] Hosseini M, Mertens SFL, Ghorbani M and Arshadi MR, Asymmetrical Schiff bases as inhibitors of mild steel corrosion in sulphuric acid media, Mater. Chem. Phys. 78 (2003), 800-808.

[14] Subramanyam NC, Sheshardi BS and Mayanna SA, Thiourea and substituted thioureas as corrosion inhibitors for aluminium in sodium nitrite solution, Corros. Sci. 34 (1993), 563-571.

[15] Domenicano A and Hargittai I, Accurate Molecular Structures, Their Determination and Importance, Oxford University Press, New York, 1992.

[16] Becke AD, Density-functionalthermochemistry. III. The role of exact exchange. J Chem Phys, 8 (1993), 5648-5653

[17] Lee C, Yang W and Parr RG, Development of the ColleSalvetti correlation-energy formula into a functional of the electron density. Phys Rev B, 37 (1988), 785-793.

[18] Frisch MJ, Trucks GW and Schlegel HB et al. 2009. Gaussian 09, Rev. A. 1 Gaussian, Inc., Wallingford CT.

[19] Tao Z, Zhang S, Li W and Hou B, Adsorption and corrosion inhibition behavior of mild steel by one derivative of benzoictriazole in acidic solution. Ind. Eng. Chem. Res., 49 (2010), 2593-2599.

[20] Emregul KC and Hayvali M, Studies on the effect of a newly synthesized Schiff base compound from phenazone and vanillin on the corrosion of steel in $2 \mathrm{M} \mathrm{HCl}$. Corros. Sci., 48 (2006), 797-812.

[21] Khaled KF, Babic-Samardzija $\mathrm{K}$ and Hackerman $\mathrm{N}$, Theoretical study of the structural effects of polymethylene amines on corrosion inhibition of iron in acid solutions. Electrochim. Acta. 50 (2005), 2515-2520.

[22] Lashkari $M$ and Arshadi MR, DFT studies of pyridine corrosion inhibitors in electrical double layer: solvent, substrate, and electric field effects. Chem J. Chem. Phys., 299 (2004), 131-137.

[23] Parr RG, Donnelly RA, Levy $M$ and Palke WE, Electronegativity- the density functional view point, $J$. Chem. Phys, 68 (1978), 3801-3807.

[24] Parr RG and Pearson RG, Absolute hardness: comparrion parameter to absolute electronegativity, J. Am. Chem. Soc, 105 (1983), 7512-7516.

[25] Koopmans T, Ordering of wave functions and eigenergies to the individual electrons of an atom. Physica, 1 (1993), 104-113.

[26] Pearson RG, Hard and soft acids and bases, J. Am. Chem. Soc, 85 (22) (1963) 3533-3539.

[27] Parr RG, Szentpaly L and Liu S, Electrophilicity index. J. Am. Chem. Soc, 121 (1999) 1922-1924. 
[28] Ayers PW, Anderson JSM and Bartolotti LJ, Perturbative perspectives on the chemical reaction prediction problem. Int. J. Quantum Chem, 101 (2005) 520-534.

[29] Khaled KF, Studies of iron corrosion inhibition using chemical, electrochemical and computer simulation techniques. Electrochim. Acta, 22 (2010) 6523.

[30] Sastri VS and Perumareddi JR. Molecular orbital theoretical studies of some organic corrosion inhibitors. Corrosion, $53,(1997) 617$.

[31] Gomez B, Likhanova NV, Dominguez-Aguilar MA, MartinezPalou R, Vela A and Gasquez, J. Quantum chemical study of the inhibitive properties of 2-pyridyl-azoles. J. Phy. Chem B. 110 (2006), 8928-8934.

[32] Udhayakala P, Rajendiran TV and Gunasekaran S, theoretical study using dft calculations on inhibitory action of some pyrazole derivatives on steel. J. Adv. Sci. Res., 3 (3) (2012), 67-74.

[33] Gece G and Bilgic S, Quantum chemical study of some cyclic nitrogen compounds as corrosion inhibitors of steel in $\mathrm{NaCl}$ media. Corros Sci., 51 (2009), 1876-1878.

[34] Awad MK, Mustafa MR and Abo Elnga MM, Computational simulation of the molecular structure of some triazoles as inhibitors for the corrosion of metal surface. J. Mol. Struct. (Theochem), 959 (2010), 66-74.

[35] Chris O Akalezi, Conrad K Enenebaku, Emeka E and Oguzie, Application of aqueous extracts of coffee senna for control of mild steel corrosion in acidic environments. Int. J. of Indus. Chem., 3 (2012) 13-25.
[36] Fleming I, Frontier Orbitals and Organic Chemical Reactions, (John Wiley and Sons, New York, 1976.

[37] Chakraborty $\mathrm{T}$ and Ghosh DC, Computation of the atomic radii through the conjoint action of the effective nuclear charge and the ionization energy. Mol. Phys., 108 (16) (2010), 2081-2092.

[38] Obi-Egbedi NO, Obot IB, El-Khaiary MI, Umoren SA and Ebenso EE, Computational simulation and statistical analysis on the relationship between corrosion inhibition efficiency and molecular structure of some phenanthroline derivatives on mild steel surface. Int. J. Electrochem. Sci., 6 (2011), 56495675 .

[39] Ebenso EE, Isabirye DA and Eddy NO, Adsorption and Quantum Chemical Studies on the Inhibition Potentials of Some Thiosemicarbazides for the Corrosion of Mild Steel in Acidic Medium. Int. J. Mol. Sci., 11 (2010), 2473-2498.

[40] Hasanov R, Sadikglu M and Bilgic S, Electrochemical and quantum chemical studies of some Schiff bases on the corrosion of steel in $\mathrm{H}_{2} \mathrm{SO}_{4}$ solution. Appl. Surf. Sci., 253 (2007), 3913-3921.

[41] Geerlings P and De Proft F, Chemical Reactivity as Described by Quantum Chemical Methods Int. J. Mol. Sci., 3 (2002), 276-309.

[42] Lukovits I, Kalman E and Zucchi F, Corrosion inhibitorscorrelation between electronic structure and efficiency. Corrosion, 57 (2001), 3-8. 